\title{
Overweight and obesity in children aged 3-13 years in urban Cameroon: a cross- sectional study of prevalence and association with socio-economic status
}

\author{
Simeon-Pierre Choukem ${ }^{1,2,3^{*}}$, Josiane Kamdeu-Chedeu ${ }^{4}$, Sam D. Leary ${ }^{5}$, Yannick Mboue-Djieka ${ }^{1}$, \\ Daniel N. Nebongo ${ }^{1}$, Christoph Akazong ${ }^{6}$, Yacouba N. Mapoure ${ }^{2,4}$, Julian P. Hamilton-Shield ${ }^{5}$, \\ Jean-François Gautier ${ }^{7}$ and Jean Claude Mbanya ${ }^{8,9,10}$
}

\begin{abstract}
Background: Childhood overweight/obesity is increasing rapidly in developing countries. There is a need to provide more evidence on its burden in sub-Saharan Africa, and to identify associated factors in order to set preventive measures. We aimed to determine the prevalence of overweight/obesity and assess its association with the socioeconomic status in nursery and primary school children in urban Cameroon.

Methods: In this cross-sectional study, we included by multi-staged cluster random sampling 1343 children from high (HSES, $n=673$ ) and low (LSES, $n=670$ ) socioeconomic status schools in Douala. Parent/child demographic data were collected, and children's anthropometric parameters were measured using validated methods. The World Health Organization body mass index-for-age reference curves were used.

Results: The prevalence of overweight/obesity was 12.5\% (13.2\% in girls, 11.8\% in boys). The risk of overweight/ obesity was 2.40 (95\% Cl 1.70, 3.40) higher in HSES children compared to LSES after adjusting for age and gender. However this association was attenuated to $1.18(95 \% \mathrm{Cl} 0.59,2.35)$ once adjustment had been made for a range of potential confounders.

Conclusions: Overweight/obesity is relatively common in sub-Saharan African children and prevalence is associated with HSES. However, this association may be mediated by sweet drink consumption, passive means of travel to school and not doing sport at school. We suggest that these potentially modifiable behaviors may be effective targets for obesity prevention. Further studies should specifically focus on unhealthy behaviors that mediate overweight/obesity as well as other non communicable diseases in children.
\end{abstract}

Keywords: Overweight, Obesity, Children, Adolescent, Prevalence, Socioeconomic status, Cameroon

\section{Background}

The prevalence of overweight and obesity in children has dramatically increased over the past two decades [1]. In 2010, 43 million children were overweight or obese -35 million of whom lived in developing countries- and this number is expected to reach 60 million by 2020 [1].

\footnotetext{
* Correspondence: schoukem@gmail.com

'Health and Human Development (2HD) Research Group, Douala, Cameroon 2Department of Internal Medicine, Douala General Hospital, P.O. Box 4856, Douala, Cameroon

Full list of author information is available at the end of the article
}

Overweight or obese children are likely to remain so in adulthood and are also at high risk of developing non communicable diseases like diabetes, hypertension, cardiovascular diseases and cancers [2]. These noncommunicable diseases are increasing alarmingly in subSaharan Africa (SSA) where infectious diseases and undernutrition in children still constitute the major focus of public health policies [3].

A recent systematic review showed rising trends of overweight and obesity in SSA children over time [4]. 
However, studies often had small sample size, lacked consistency regarding a uniform definition of overweight/obesity, or did not used standardized age groups; all the above make comparisons of studies inaccurate. Recent reports in Nigeria show prevalence of combined overweight and obesity of 3.5\% in 1016 urban primary school children aged 6-10 years using the World Health Organization (WHO) reference [5] and 11.6\% in 1302 urban primary school children 6-12 years using the CDC reference growth charts [6].

Socio-economic status (SES) is potentially a major risk factor for childhood obesity. In developed countries, recent studies confirm the well known inverse association, children from low socioeconomic status having a higher prevalence of obesity compared with those from higher socioeconomic status [7]. In low and middle income countries, data from South-Asian, the Far East and South-American populations demonstrated that high socio-economic status is associated with higher rates of overweight/obesity in children [8]. In low-income SSA countries studies are rare. A recent report in Cameroonian children aged 5 to 12 years showed findings similar to other low-income countries -high SES associated with overweight/obesity with an odds ratio (95\% confidence interval) of $10.1(5.4,18.9)$ as compared with low SES. However, SES in that study was not a predefined predictor, and adjustment was made only for height standard deviations and birth weight [9]. Moreover, data are almost nonexistent for the age group under 5 years. As longitudinal studies have shown that early BMI or adiposity rebound by 43 months of age is one of the major independent risk factors for further childhood obesity, [10] this age group may be of particular interest for interventions and to estimate the future burden of obesity in older age groups.

Sustainable public health strategies aiming to tackle the emerging childhood and adolescent obesity in SSA can only be developed if sufficient evidence of its burden and risk factors is available. We therefore aimed to determine the prevalence of childhood overweight and obesity and assess its association with the socioeconomic status, adjusting for a wide range of confounders, in randomly selected nursery and primary schools in an urban area of Cameroon. We hypothesized that high SES is associated with overweight/obesity after adjustment for these confounders.

\section{Methods}

\section{Study design and population}

This was a cross-sectional study conducted in Douala, the biggest city of Cameroon with an estimated population of 2.446.945 inhabitants in 2011. Neighborhoods in Douala are classified by the National Institute of Statistics (NIS) as low, medium and high socio-economic status using various indicators [11]. The survey that provided data for this ranking was based on a random sampling of 7500 households per city (Douala and Yaoundé). The main indicators used in classification were the annual income and the housing status. The same NIS-based ranking of neighborhoods was used to select schools in a previous study that assessed the role of SES in adolescents' nutritional status in Yaoundé [12]. The Primary school net enrolment ratio in Cameroon was estimated at $93.5 \%$ in $2008-2011$ by the United Nations International Children's Emergency Fund [13]. Thus, a sample from nursery and primary schools is likely to be representative of children living in Douala.

We performed a multi-staged cluster random sampling that consisted of: 1) random selection by balloting of one area of low socio-economic status (LSES) and one area of medium-to-high socio economic status (HSES) in the city of Douala; 2) census of all nursery and primary schools in each area and census of the number of pupils per school; 3) random selection of schools per area until the target sample size with an additional 25\% was reached. Five schools were selected in Bonamoussadi-Makepe (HSES) and five in Boko Village (LSES). Because Bonamoussadi-Makepe is a mixture of middle and high SES, we merged the two SES in one group. All children aged 3 years and above were invited to participate through a letter to their parents.

\section{Sample size and power calculation}

According to the EDS-MICS (Enquête Démographique et de Santé et à Indicateurs Multiples) survey in 2011, [14] the prevalence of childhood overweight and obesity in Cameroon was $6 \%$. Our study was designed to detect a $40 \%$ higher prevalence in children from HSES schools (7\%) compared with those from LSES schools (5\%), with a type I error of 5\%, two-sided tests, and a power of $80 \%$. The minimum sample was 619 participants per group (total 1238).

\section{Data collection and classification of the nutritional status}

Data were collected between February and March 2013 using a questionnaire. Information letters, consent forms (in duplicates) and questionnaires were handed to each class teacher who put them in each child's school bag along with their daily homework. Parents had to retrieve these documents and read and sign the information letter. Those who agreed to let their children participate in the study also signed the informed consent forms, filled in the first part of the questionnaire and put them in their child's school bag. These forms were collected back by the teacher and handed to our team. A copy of the signed informed consent was returned to parents through the same means. The questionnaire contained personal and social data on the child (date of birth, birth weight, eating habits including early feeding, physical 
activity during school and leisure time, means of travel to school, sleeping habits, electronic and television use habits, and receipt of pocket money), their mother (age, education level, smoking and alcohol habits, weight and height), and their father (education level). Physical activity in school was confirmed by the teacher.

Children thereafter had their anthropometry (weight in $\mathrm{kg}$ and standing height in $\mathrm{cm}$ ) measured within 7 days by a team of trained doctors who followed preestablished standard operating procedures. The weight to the nearest $100 \mathrm{~g}$ was measured using a Camry bathroom scale, and the height to the nearest $0.5 \mathrm{~cm}$ was measured using a Leicester ${ }^{\bullet}$ stadiometer. The body mass index (BMI) was calculated $\left(\mathrm{kg} / \mathrm{m}^{2}\right)$. All measurements were made once with the child bare foot and wearing light clothes. All children were measured using the same brand of scale and stadiometer. The scales were readjusted to zero after each measurement.

To determine the participant's nutritional status, the BMI was plotted against the WHO body mass indexfor-age reference curves for $0-5$ years[15] and 5-19 years [16].

\section{Statistical analysis}

Stata version 13 was used for data analysis. Continuous variables (all approximately normally distributed) were summarized by means and standard deviations, and categorical variables were summarized by proportions. Variables were summarized for the whole group, and also separately for HSES and LSES; the latter were compared using $\mathrm{t}$-tests or chi-square tests as appropriate. The prevalence of overweight/obesity was calculated using proportions with $95 \%$ confidence intervals $(\mathrm{CI})$; values are given for the whole cohort, boys and girls separately, each age group separately, and each social class group separately. Associations between each variable and overweight/obesity were assessed using random effects logistic models; random effects were used to account for the dependence of children within the same school. A series of models were fitted with socio-economic status as the predictor and overweight/obesity as the outcome, adjusting for the following potential confounders: model 1 adjusted only for age and gender; model 2 adjusted for age, gender and early life factors (birth weight, type of feeding from 0 to 6 months); model 3 adjusted for age, gender and parental factors (mother's age, BMI, education level, alcohol consumption, and father's education level); model 4 adjusted for age, gender, early life factors and parental factors; model 5 adjusted for age, gender and current child factors (number of meals per day, fruit consumption, sweet drink consumption, physical activity at school and leisure time, travel means to school, sleeping habits, electronic and television use habits, time child wakes up, daytime sleep and receipt of pocket money); and model 6 adjusted for all potential confounders. Variance inflation factors were calculated for each potential confounder, and as the maximum value was 1.6, all variables were included in the final model.

\section{Ethical considerations}

Ethical approval was obtained from the National Ethics Committee ( ${ }^{\circ}$ 2013/05/322/CNERSH/SP) and administrative clearances from the regional delegation for basic education and directors of selected schools. Children were included only if parents signed the information letter and the informed consent form.

\section{Results}

\section{General characteristics of participants}

We included 1343 children aged 3-13 years -673 from middle-to-high socioeconomic status (HSES) schools and 670 from low socioeconomic level (LSES) schools (Fig. 1). Compared with LSES children, children from HSES were less likely to have been breast-fed during the first six months of life, more likely to have three regular meals per day, to have regular fruit consumption and to consume sweet drinks regularly. They also were more likely to have a daytime 'nap', have greater 'electronic screen-time', and to be passively transported to school, and less likely to play sport at school and to have pocket money (Additional file 1). Parents of HSES children had higher level of education and their mothers drank less alcohol (Additional file 1). Children from HSES schools had higher weight, height and BMI compared with those from LSES schools (Table 1). The distribution of other categorical and continuous variables was similar between the two groups (Additional file 1 and Table 1).

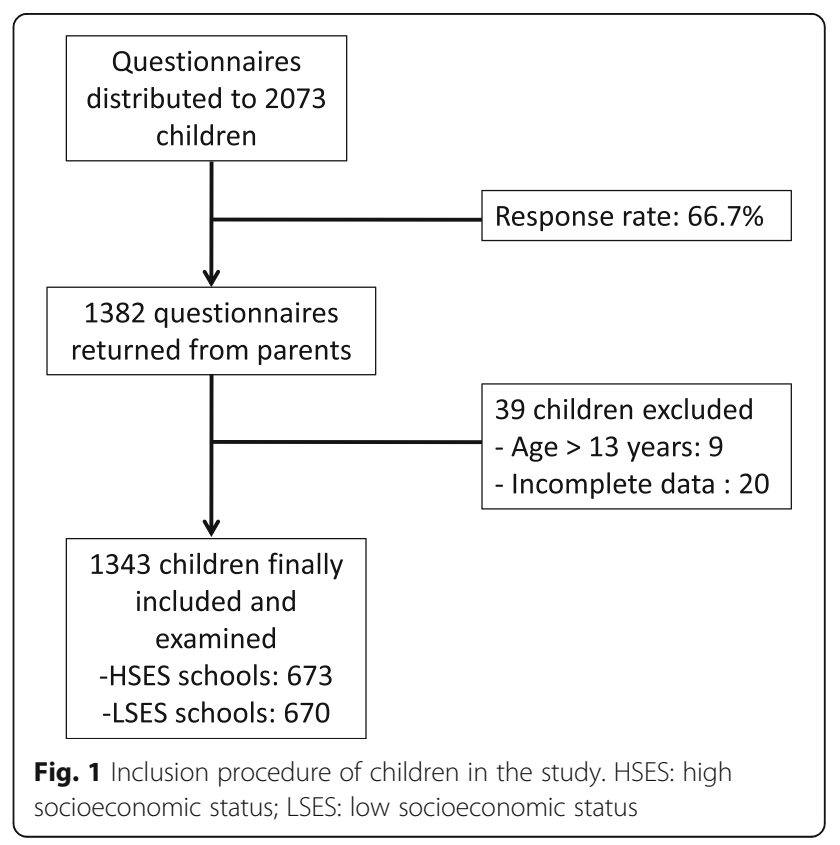


Table 1 Summary of all continuous variables for the whole cohort and separately for HSES and LSES

\begin{tabular}{|c|c|c|c|c|c|c|c|}
\hline & Whole & & HSES & & LSES & & $p$ \\
\hline & $N$ & Mean (SD) & $N$ & Mean (SD) & $\bar{N}$ & $\overline{\text { Mean }(S D)}$ & \\
\hline Age (years) & 1343 & $8.0(2.4)$ & 673 & $8.0(2.3)$ & 670 & $8.1(2.5)$ & 0.4 \\
\hline Birth weight (kg) & 960 & $3.3(0.6)$ & 482 & $3.2(0.6)$ & 478 & $3.3(0.6)$ & 0.2 \\
\hline Maternal age (years) & 1131 & $35.0(6.0)$ & 610 & $35.1(6.1)$ & 521 & $35.0(5.9)$ & 0.8 \\
\hline Maternal weight (kg) & 1081 & $72.1(12.1)$ & 556 & $72.5(12.4)$ & 482 & $71.6(11.9)$ & 0.2 \\
\hline Maternal height $(\mathrm{cm})$ & 1038 & $163.1(8.2)$ & 581 & $163.5(8.5)$ & 500 & $162.6(7.9)$ & 0.1 \\
\hline Maternal BMI $\left(\mathrm{kg} / \mathrm{m}^{2}\right)$ & 993 & $27.3(5.0)$ & 539 & $27.3(5.1)$ & 454 & $27.3(4.9)$ & 0.99 \\
\hline Child weight (kg) & 1343 & $25.3(7.9)$ & 673 & $26.4(8.4)$ & 670 & $24.2(7.2)$ & $<0.001$ \\
\hline Child height $(\mathrm{cm})$ & 1343 & $124.6(14.6)$ & 673 & $126.2(14.7)$ & 670 & $123.0(14.3)$ & $<0.001$ \\
\hline Child BMI $\left(\mathrm{kg} / \mathrm{m}^{2}\right)$ & 1343 & $15.9(2.2)$ & 673 & $16.2(2.4)$ & 670 & $15.7(1.9)$ & $<0.001$ \\
\hline BMI children $<6$ years & 222 & $15.5(2.0)$ & 104 & $15.7(2.2)$ & 118 & $15.4(1.9)$ & 0.35 \\
\hline BMI children 6-10 years & 896 & $15.7(2.1)$ & 466 & $16.0(2.3)$ & 430 & $15.5(1.7)$ & $<0.001$ \\
\hline BMI children $>10$ years & 225 & $17.1(2.4)$ & 103 & $17.7(2.6)$ & 122 & $16.7(2.1)$ & 0.002 \\
\hline
\end{tabular}

$B M I$ body mass index, HSES High socioeconomic status, LSES Low socioeconomic status, SD standard deviation; *p-value from t-tests, HSES vs. LSES

\section{Prevalence of overweight and obesity}

The overall prevalence of overweight $(9.6 \%)$ and obesity (2.9\%) combined was $12.5 \%$ (95\% CI 10.8, 14.4) (Table 2). This prevalence was $11.8 \%$ in boys and $13.2 \%$ in girls, $17.1 \%$ in children from HSES schools and $7.9 \%$ in those from LSES schools (Table 2).

\section{Associations between potential confounders and overweight/obesity}

Based on univariate models (Table 3), lower age, higher birth weight, higher sweet drink consumption, passive means of travel to school, not doing sport at school and higher maternal BMI were positively associated with overweight and obesity. There were no strong associations between any of the other potential confounders and overweight/obesity.

\section{Associations between socio-economic status and over- weight/obesity}

After adjustment for only age and gender (model 1), HSES was associated with a $2.40(95 \%$ CI 1.70, 3.40) higher risk of overweight/obesity compared to LSES (Table 4). After additional adjustment for either early life factors, parental factors, or current child factors, the risk attenuated a little, to approximately twice as high for HSES compared to LSES (Table 4). However, after adjustment for all potential confounders the risk attenuated to only 1.18 (95\% CI $0.59,2.35)$ times higher for HSES compared to LSES (Table 4). Adjusting for all confounders reduced the sample size from 1343 to 620, however when model 1 was re-fitted restricted to this sample, the risk of overweight/obesity was still almost doubled $(\mathrm{OR}=1.95 ; 95 \% \mathrm{CI} 1.18,3.23 ; p=0.01)$ for HSES compared to LSES.

\section{Discussion}

We have shown in this study that the prevalence of overweight and obesity in nursery and primary school children aged 3-13 years was $12.5 \%$, without any statistical evidence of a gender difference. This prevalence is twice that reported in the EDS-MICS; the EDS-MICS included rural areas of the country, which diluted the prevalence [14]. We have also shown that high socioeconomic status (HSES) was strongly associated with overweight/obesity, with HSES schools children being almost two and half times more likely to be overweight or obese than those from low socio-economic status (LSES) schools. However, the increased risk with the HSES appeared to be driven by other factors, since the association was attenuated when all potential confounders were included in the regression model.

The prevalence we report here indicates a high burden of overweight and obesity in children in this urban area of sub-Saharan Africa (SSA) where infectious diseases and malnutrition are yet to be tackled [3]. Another recent study in Cameroon found a prevalence of overweight and obesity of $17.9 \%$ in urban children aged $8-$ 15 years using the WHO references [17]. Studies in other sub-Saharan African countries have reported prevalence levels of overweight and obesity that vary according to the area and criteria used to define it: $3.5 \%$ in 1016 primary school children aged 6-10 years in urban South-western Nigeria using the WHO references; [5] $11.6 \%$ in 1302 primary school children aged 6-12 years in urban south-eastern Nigeria using the CDC references, [6] and $13.4 \%$ in the subgroup of 4833 Black children aged 6-13 years in South Africa, using the IOTF criteria [18]. All the aforementioned studies used objective measurements to define overweight and obesity. The prevalence in our population is therefore close to the 
Table 2 Prevalence of overweight/obesity: whole cohort, by gender, by age-group and by SES

\begin{tabular}{|c|c|c|c|}
\hline & $\begin{array}{l}\text { Prevalence (95\% } \\
\text { Cl) }\end{array}$ & & \\
\hline \multicolumn{4}{|l|}{ Whole cohort } \\
\hline $\begin{array}{l}\text { Overweight/ } \\
\text { obesity }\end{array}$ & \multicolumn{3}{|l|}{$12.5(10.8,14.4) \%$} \\
\hline $\begin{array}{l}\text { Normal/ } \\
\text { underweight }\end{array}$ & \multicolumn{3}{|l|}{$87.5(85.6,89.2) \%$} \\
\hline Obesity & \multicolumn{3}{|l|}{$2.9(2.1,4.0) \%$} \\
\hline Overweight & \multicolumn{3}{|l|}{$9.6(8.1,11.3) \%$} \\
\hline Normal weight & \multicolumn{3}{|l|}{$83.6(81.5,85.5) \%$} \\
\hline Underweight & \multicolumn{3}{|l|}{$3.9(3.0,5.0) \%$} \\
\hline By gender & Boys & \multicolumn{2}{|l|}{ Girls } \\
\hline $\begin{array}{l}\text { Overweight/ } \\
\text { obesity }\end{array}$ & $11.8(9.5,14.5) \%$ & \multicolumn{2}{|l|}{$\begin{array}{l}13.2(10.9 \\
16.0) \%\end{array}$} \\
\hline $\begin{array}{l}\text { Normal/ } \\
\text { underweight }\end{array}$ & $88.2(85.5,90.5) \%$ & \multicolumn{2}{|l|}{$\begin{array}{l}86.8(84.0 \\
89.1) \%\end{array}$} \\
\hline Obesity & $2.6(1.6,4.1) \%$ & \multicolumn{2}{|l|}{$3.2(2.1,4.8) \%$} \\
\hline Overweight & $9.2(7.2,11.6) \%$ & \multicolumn{2}{|l|}{$\begin{array}{l}10.0(8.0 \\
12.5) \%\end{array}$} \\
\hline Normal weight & $84.4(81.4,87.0) \%$ & \multicolumn{2}{|l|}{$\begin{array}{l}82.8(79.8 \\
85.5) \%\end{array}$} \\
\hline Underweight & $3.8(2.6,5.6) \%$ & \multicolumn{2}{|l|}{$3.9(2.7,5.7) \%$} \\
\hline By age groups & $<6$ years & 6-10years & $>10$ years \\
\hline $\begin{array}{l}\text { Overweight/ } \\
\text { obesity }\end{array}$ & $17.6(13.1,23.2) \%$ & $\begin{array}{l}11.6(9.7 \\
13.9) \%\end{array}$ & $\begin{array}{l}11.1(7.6 \\
16.0) \%\end{array}$ \\
\hline $\begin{array}{l}\text { Normal/ } \\
\text { underweight }\end{array}$ & $82.4(76.8,86.9) \%$ & $\begin{array}{l}88.4(86.1 \\
90.3) \%\end{array}$ & $\begin{array}{l}88.9(84.0, \\
92.4) \%\end{array}$ \\
\hline Obesity & $4.1(2.1,7.6) \%$ & $2.9(2.0,4.2) \%$ & $1.8(0.7,4.7) \%$ \\
\hline Overweight & $13.5(9.6,18.7) \%$ & $8.7(7.0,10.7) \%$ & $9.3(6.1,13.9) \%$ \\
\hline Normal weight & $78.8(72.9,83.7) \%$ & $\begin{array}{l}84.8(82.3 \\
87.0) \%\end{array}$ & $\begin{array}{l}83.6(78.1 \\
87.8) \%\end{array}$ \\
\hline Underweight & $3.6(1.8,7.1) \%$ & $3.6(2.5,5.0) \%$ & $5.3(3.0,9.2) \%$ \\
\hline By SES & HSES & LSES & \\
\hline $\begin{array}{l}\text { Overweight/ } \\
\text { obesity }\end{array}$ & $17.1(14.4,20.1) \%$ & $7.9(6.1,10.2) \%$ & \\
\hline $\begin{array}{l}\text { Normal/ } \\
\text { underweight }\end{array}$ & $82.9(79.9,85.6) \%$ & $\begin{array}{l}92.1(89.8 \\
93.9) \%\end{array}$ & \\
\hline Obesity & $4.3(3.0,6.1) \%$ & $1.5(0.8,2.8) \%$ & \\
\hline Overweight & $12.8(10.5,15.5) \%$ & $6.4(4.8,8.5) \%$ & \\
\hline Normal weight & $78.8(75.5,81.7) \%$ & $\begin{array}{l}88.5(85.9 \\
90.7) \%\end{array}$ & \\
\hline Underweight & $4.2(2.9,6.0) \%$ & $3.6(2.4,5.3) \%$ & \\
\hline
\end{tabular}

Cl confidence interval, HSES High socioeconomic status, LSES Low socioeconomic status, SES Socioeconomic status

upper limit of the range in SSA. Figures are much more alarming in developed countries. In the USA for instance, overweight and obesity concerned $26.7 \%$ of children aged $2-5$ years and $32.6 \%$ of those aged $6-11$ years in 2009-2010 [19].
Table 3 Associations between potential confounders and overweight/obesity in univariate models

\begin{tabular}{|c|c|c|c|}
\hline Potential confounders & Categories & OR $(95 \% \mathrm{Cl})$ & $\begin{array}{l}P \\
\text { value }^{*}\end{array}$ \\
\hline Gender (vs. male) & Female & $1.16(83.9,1.62)$ & 0.4 \\
\hline Age (per year) & - & $0.92(0.86,0.98)$ & 0.01 \\
\hline Birthweight (per $100 \mathrm{~g}$ ) & - & $1.01(1.002,1.009)$ & 0.001 \\
\hline \multirow{2}{*}{$\begin{array}{l}\text { Type of feeding from } 0 \text { to } \\
6 \text { months (vs. breast milk) }\end{array}$} & Formula & $1.92(0.79,4.68)$ & 0.2 \\
\hline & $\begin{array}{l}\text { Breast milk and } \\
\text { formula }\end{array}$ & $1.15(0.81,1.63)$ & 0.4 \\
\hline \multirow{2}{*}{$\begin{array}{l}\text { Number of meals per day } \\
\text { (vs. 1-2) }\end{array}$} & 3 & $1.22(0.72,2.10)$ & \multirow[t]{2}{*}{0.06} \\
\hline & $4+$ & $1.76(0.94,3.30)$ & \\
\hline \multirow{2}{*}{$\begin{array}{l}\text { Fruit consumption (vs. 4-7 } \\
\text { times/week) }\end{array}$} & 1-3 times/week & $0.54(0.35,0.85)$ & \multirow[t]{2}{*}{0.1} \\
\hline & $<1 /$ week & $0.63(0.40,0.99)$ & \\
\hline \multirow{2}{*}{$\begin{array}{l}\text { Sweet drink consumption } \\
\text { (vs. never/rarely) }\end{array}$} & Often & $1.42(0.997,2.02)$ & \multirow[t]{2}{*}{0.01} \\
\hline & Everyday & $1.98(1.12,3.51)$ & \\
\hline Leisure time sport (vs. yes) & No & $0.97(0.69,1.35)$ & 0.8 \\
\hline $\begin{array}{l}\text { Passive travel to school } \\
\text { (vs. walk/cycle) }\end{array}$ & $\begin{array}{l}\text { Motorcycle/taxi/ } \\
\text { car/public } \\
\text { transport }\end{array}$ & $1.95(1.28,2.95)$ & 0.002 \\
\hline School sport (vs. yes) & No & $2.08(1.24,3.48)$ & 0.01 \\
\hline \multirow{2}{*}{$\begin{array}{l}\text { Time watching screen } \\
\text { (vs. }<1 \text { h/day) }\end{array}$} & 1-2 h/day & $1.16(0.77,1.74)$ & \multirow[t]{2}{*}{0.2} \\
\hline & $2+$ hour/day & $1.35(0.87,2.11)$ & \\
\hline $\begin{array}{l}\text { Time child wakes up (vs. } \\
\text { between } 6 \text { am and } 7 \text { am) }\end{array}$ & $\begin{array}{l}\text { Between } 3 \mathrm{am} \\
\text { and } 5.55 \mathrm{am}\end{array}$ & $0.82(0.57,1.18)$ & 0.3 \\
\hline Daytime sleep (vs. yes) & No & $0.94(0.66,1.35)$ & 0.7 \\
\hline Pocket money (vs. yes) & No & $1.02(0.72,1.44)$ & 0.9 \\
\hline Maternal age (per year) & - & $1.01(0.99,1.04)$ & 0.3 \\
\hline Maternal BMI (per kg/m²) & - & $1.06(1.02,1.09)$ & 0.002 \\
\hline \multirow{3}{*}{$\begin{array}{l}\text { Maternal education level } \\
\text { (vs. university) }\end{array}$} & High school & $1.09(0.67,1.78)$ & \multirow[t]{3}{*}{0.1} \\
\hline & $\begin{array}{l}\text { Secondary } \\
\text { school }\end{array}$ & $0.82(0.50,1.36)$ & \\
\hline & $\begin{array}{l}\text { None/Primary } \\
\text { school }\end{array}$ & $0.68(0.37,1.25)$ & \\
\hline $\begin{array}{l}\text { Maternal alcohol } \\
\text { consumption (vs. yes) }\end{array}$ & No & $1.50(0.92,2.43)$ & 0.1 \\
\hline \multirow[t]{3}{*}{$\begin{array}{l}\text { Paternal education level } \\
\text { (vs. university) }\end{array}$} & $\begin{array}{l}\text { High school } \\
\text { Secondary }\end{array}$ & $0.78(0.52,1.18)$ & \multirow[t]{3}{*}{0.08} \\
\hline & school & $0.59(0.36,0.97)$ & \\
\hline & $\begin{array}{l}\text { None/Primary } \\
\text { school }\end{array}$ & $0.75(0.41,1.37)$ & \\
\hline
\end{tabular}

$O R$ odds ratio, $\mathrm{Cl}$ confidence interval; ${ }^{*}$-value for trend if ordinal variable has more than two categories

Studies that have included children below 5 years of age in SSA are very rare, but show prevalence of overweight and obesity as high as $22 \%$ [20]. In that specific age group, we also observed a higher prevalence of overweight/obesity (17.6\%) compared with older children (11.6\% in $6-10$ year-old children and $11.1 \%$ in $10-13$ year-old ones). This may indicate a future worsening of overweight/obesity in older age groups as shown in the 
Table 4 Associations between SES and overweight/obesity in multivariate models

\begin{tabular}{|c|c|c|c|}
\hline Outcome HSES vs. LSES & $\begin{array}{l}\text { Adjusted } \\
\text { OR }\end{array}$ & $95 \% \mathrm{Cl}$ & $P$ value \\
\hline Model 1 [Adjusted for age and gender] & 2.40 & $1.70,3.40$ & $<0.001$ \\
\hline $\begin{array}{l}\text { Model } 2 \text { [Adjusted for age, gender } \\
\text { and early life factors*] }\end{array}$ & 2.23 & $1.45,3.45$ & $<0.001$ \\
\hline $\begin{array}{l}\text { Model } 3 \text { [Adjusted for age, gender } \\
\text { and parental factors }{ }^{a} \text { ] }\end{array}$ & 2.20 & $1.38,3.52$ & 0.001 \\
\hline $\begin{array}{l}\text { Model } 4 \text { [Adjusted for age, gender, } \\
\text { early life factors and parental factors] }\end{array}$ & 1.94 & $1.13,3.36$ & 0.02 \\
\hline $\begin{array}{l}\text { Model } 5 \text { [Adjusted for age, gender } \\
\text { and current child factors }{ }^{\mathrm{a}} \text { ] }\end{array}$ & 1.93 & $1.21,3.07$ & 0.005 \\
\hline $\begin{array}{l}\text { Model } 6 \text { [Adjusted for all potential } \\
\text { confounders] }\end{array}$ & 1.18 & $0.59,2.35$ & 0.6 \\
\hline
\end{tabular}

OR odds ratio, $\mathrm{Cl}$ confidence interval, SES socioeconomic status *Type of feeding 0-6 months, birth weight

${ }^{\dagger}$ Maternal age, maternal BMI, maternal education, maternal alcohol consumption, paternal education

${ }^{a}$ Number of meals per day, fruit consumption, sweet drink consumption, leisure time sport, travel to school, school sport, time watching screen, time child wakes up, daytime nap, pocket money

Avon Longitudinal Study of Parents and Children cohort study where early BMI or adiposity rebound by 43 months of age was one of the major independent risk factors (15-fold increased risk) for further childhood obesity [10].

We found that the socio-economic status (SES) was positively associated with overweight/obesity. Socio-economic status is considered as one of the major risk factors of childhood obesity. In developed countries, a negative gradient has long been described between the SES and overweight/obesity, and has recently been confirmed in children [7]. The relationship between the SES and overweight/obesity is known to be positive in adults in developing countries [21]. A similar pattern was observed recently in children aged 5-12 years in Cameroon, but SES was not a predefined predictor, and adjustment was made only for height standard deviations and birth weight [9]. Thus, whether the consideration of potential confounders would keep the independence of the association of childhood overweight/obesity with SES was not known. SES is a combination or a trigger of behavioral or parental factors that may individually play a direct role in the risk of overweight/obesity. Our observation of the attenuation of the association between SES and overweight/obesity in the model including all confounders suggest that other factors probably come into play. This attenuation was more prominent when current child factors were added to age and gender in the model, and there was no statistical evidence for an association between SES and overweight/obesity once all confounders were considered. It is possible that models 5 and 6 could be over-adjustments, and we hypothesize that current child factors, especially those that were strongly associated with overweight/obesity in the univariate model -higher sweet drink consumption, passive means of travel to school and not doing sport at school- are potential mediators in the association between HSES and overweight/obesity in our population. These factors are indeed indicators of HSES and have been reported by others to be associated with childhood overweight/obesity. For instance, consumption of sugary drinks was found to be strongly associated with childhood obesity in a systematic review of thirty studies [22]. Active transport to school is an important means to ensure permanent moderate physical activity in children [23]. Its role may be more prominent in a developing country like Cameroon where children in rural as well as urban areas may walk for miles every day to and from their financially accessible school. This finding also has public health relevance regarding the promotion of active transport by walking or cycling.

The major limitation of our study is its cross-sectional design that does not allow us to evaluate the impact of the SES and other potential risk factors we have identified. However, we have used a multistage cluster sampling to select a population that probably represent the general children population of the city, as the primary school net enrolment ratio in Cameroon was estimated at $93.5 \%$ in $2008-2011$ [13]. Also, as parental data, birth weight and child demographic data were reported by parents, self-reporting bias is another potential limitation. To overcome this, we cross-checked the data with children's school files in case of doubt. Amongst other potential limitations is the use of neighborhood as the main criterion for SES, as children from one neighborhood may go to school in another part of the city of different SES. In addition, the psychometric properties of the questionnaire have not been assessed independently in other studies. Finally, our sample may not be nationally representative so generalizability is currently unproven.

\section{Conclusions}

Overweight/obesity is highly prevalent in urban subSaharan African children. It is strongly positively associated with SES, but this association may be mediated by behavioral socioeconomic indicators like sweet drink consumption, passive mean of travel to school and not doing sport at school. Our results suggest that strategies to tackle children overweight/ obesity in SSA should consider these modifiable factors. Further studies should specifically focus on unhealthy behaviors that mediate overweight/obesity as well as other non communicable diseases in children. 


\section{Additional file}

Additional file 1. Summary of all categorical variables; whole cohort and separately for HSES and LSES. HSES = High socioeconomic status; LSES = Low socioeconomic status; IQR = inter-quartile range; ${ }^{*} \mathrm{p}$-value from chi-squared tests, HSES vs.LSES; ${ }^{\dagger}$ of those who receive pocket money, median $(\mathrm{IQR})=150(100,200)$ FCFA. (DOCX 16 kb)

\section{Abbreviations}

BMI: Body mass index; CDC: Centers for disease control and prevention; $\mathrm{Cl}$ : Confidence interval; EDS-MICS: Enquête démographique et de santé et à indicateurs multiples; HSES: High socio-economic status; IOTF: International obesity task force; LSES: Low socio-economic status; OR: Odd ratio; SES: Socio-economic status; SSA: Sub-Saharan Africa; USA: United States of America; WHO: World health organization

\section{Acknowledgements}

The authors are grateful to children, parents and directors of schools who accepted to participate in this study. We also thank the members of the Douala Research Network for their contribution in improving the proposal. The 2HD Research Group is supported by a Cruddas Link Fellowship to SPC (Tseu Medical Institute, Harris Manchester College, University of Oxford, UK) and receives technical assistance from the NIHR-Bristol Biomedical Research Unit (BRU) in Nutrition, University of Bristol, UK.

\section{Funding}

This work was funded by a research grant from the Francophone Diabetes Society (SFD) to SPC. JPHS and SDL's research receives funding support through the NIHR Biomedical Research Unit funding scheme (UK).

\section{Availability of data and materia}

The datasets generated during and/or analyzed during the current study are not publicly available -because some secondary manuscripts are still being written- but are available from the corresponding author on reasonable request.

\section{Authors' contribution}

SPC: conception and design of the study, data collection, data interpretation, drafting and review of the manuscript.

JKC: conception and design of the study, data collection, drafting and review of the manuscript.

JFG: conception and design of the study, data collection, drafting and review of the manuscript.

JCM: conception and design of the study, data collection, drafting and review of the manuscript.

SDL: data analysis, data interpretation, drafting and review of the manuscript. YMD: data collection, data interpretation, drafting and review of the manuscript.

DNN: data collection, data interpretation, drafting and review of the manuscript.

CA: data interpretation, drafting, editing and review of the manuscript. YNM: data interpretation, drafting, editing and review of the manuscript. JPHS: data interpretation, drafting, editing and review of the manuscript. All authors revised and approved the final version of the manuscript.

\section{Competing interests}

The authors declare that they have no competing interests.

\section{Consent for publication}

Not applicable.

\section{Ethics approval and consent to participate}

Ethical approval was obtained from the National Ethics Committee for Research in Human Health (N²013/05/322/CNERSH/SP) and administrative clearances from the regional delegation for basic education and directors of selected schools. The ethical committee approved the whole study protocol without any reserve, and it was clearly indicated in the study procedure that information and consent forms will be sent to parents through children's school bags.
A note was included in the information letter that in view of the personal information in the questionnaire, we advice the parents to return the documents in sealed envelopes to ensure confidentiality. Children were included only if parents signed the information letter and the informed consent form, and if they verbally accepted to be examined. Confidentiality and respect of children's intimacy were fully ensured during the study.

\section{Author details}

${ }^{1}$ Health and Human Development (2HD) Research Group, Douala, Cameroon. 2Department of Internal Medicine, Douala General Hospital, P.O. Box 4856, Douala, Cameroon. ${ }^{3}$ Department of Internal Medicine and Pediatrics, Faculty of Health Sciences, University of Buea, Buea, Cameroon. ${ }^{4}$ Faculty of Medicine and Pharmaceutical Sciences, University of Douala, Douala, Cameroon. ${ }^{5}$ Biomedical Research Unit in Nutrition, Diet and Lifestyle, University of Bristol, Bristol, UK. ${ }^{6}$ Department of Pediatrics, Douala General Hospital, Douala, Cameroon. ${ }^{7}$ Department of Diabetes, Endocrinology and Nutrition, Assistance Publique - Hôpitaux de Paris, Lariboisière Hospital, University Paris-Diderot Paris-7, 2 rue Ambroise Paré, 75010 Paris, France. ${ }^{8}$ National Centre of Obesity, Diabetes and Endocrinology, Yaoundé Central Hospital,

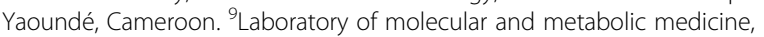
Biotechnology Center, University of Yaoundé 1, Yaoundé, Cameroon. ${ }^{10}$ Department of Internal Medicine and Subspecialties, Faculty of Medicine and Biomedical Sciences, University of Yaoundé 1, Yaoundé, Cameroon.

Received: 17 January 2016 Accepted: 28 January 2017

Published online: 01 February 2017

\section{References}

1. de Onis M, Blossner M, Borghi E. Global prevalence and trends of overweight and obesity among preschool children. Am J Clin Nutr. 2010; 92(5):1257-64.

2. Must A, Strauss RS. Risks and consequences of childhood and adolescent obesity. Int J Obes Relat Metab Dis: J Int Assoc Stud Obes. 1999:23 Suppl 2:S2-11.

3. World Bank. The global burden of disease: main findings for SubSaharan Africa. 2013. http://www.worldbank.org/en/news/feature/2013/ 09/09/global-burden-of-disease-findings-for-sub-saharan-africa. Accessed 9 Mar 2015

4. Muthuri SK, Francis CE, Wachira LJ, Leblanc AG, Sampson M, Onywera VO, et al. Evidence of an overweight/obesity transition among school-aged children and youth in Sub-Saharan Africa: a systematic review. PLoS One. 2014;9(3):e92846.

5. Fetuga MB, Ogunlesi TA, Adekanmbi AF, Alabi AD. Nutritional status of semi-urban Nigerian school children using the 2007 WHO reference population. West Afr J Med. 2011;30(5):331-6.

6. Okoh BA, Alikor EA, Akani N. Prevalence of hypertension in primary school-children in port Harcourt, Nigeria. Paediatr Int child health. 2012;32(4):208-12

7. Bammann K, Gwozdz W, Lanfer A, Barba G, De Henauw S, Eiben G, et al. Socioeconomic factors and childhood overweight in Europe: results from the multi-centre IDEFICS study. Pediatr Obes. 2013;8(1):1-12.

8. Dinsa GD, Goryakin Y, Fumagalli E, Suhrcke M. Obesity and socioeconomic status in developing countries: a systematic review. Obesity Rev. 2012; 13(11):1067-79.

9. Navti LK, Ferrari U, Tange E, Bechtold-Dalla Pozza S, Parhofer KG. Contribution of socioeconomic status, stature and birth weight to obesity in Sub-Saharan Africa: cross-sectional data from primary school-age children in Cameroon. BMC Public Health. 2014;14:320.

10. Reilly JJ, Armstrong J, Dorosty AR, Emmett PM, Ness A, Rogers I, et al. Early life risk factors for obesity in childhood: cohort study. BMJ. 2005; 330(7504):1357.

11. Institut National de la Statistique. Enquête sur le cadre de vie des population de Yaoundé et de Douala en 2002. Volume 1: Méthodologie de l'enquête et synthèse des résultats de l'ECAM II sur l'activité et la consommation des ménages. In: Statistique INdl, ed. Cameroon: Institut National de la Statistique, 2003:38.

12. Dapi LN, Janlert U, Nouedoui C, Stenlund H, Haglin L. Socioeconomic and gender differences in adolescents' nutritional status in urban Cameroon, Africa. Nutr Res. 2009;29(5):313-9. 
13. United Nation International Children Emergency Fund. Cameroon statistics. Secondary Cameroon statistics 2012. http://www.unicef.org/infobycountry/ cameroon_statistics.html. Accessed 30 Apr 2015.

14. Institut National de la Statistique, Ministère de l'Economie, du Plan et de I'Aménagement du Territoire, Minsistère de la Santé Publique. Enquête Démographique et de Santé et à Indicateurs Multiples. Secondary Enquête Démographique et de Santé et à Indicateurs Multiples 2011. http://www. statistics-cameroon.org/downloads/EDS-MICS11/EDS-MICS4_Note_de_ presentation_14_nov_11.pdf. Accessed 20 Dec 2012.

15. World Health Organisation. Construction of the body mass index-for-age standards. Secondary Construction of the body mass index-for-age standards. http://www.who.int/childgrowth/standards/Chap_6.pdf?ua=1. Accessed 5 Feb 2013.

16. de Onis M, Onyango AW, Borghi E, Siyam A, Nishida C, Siekmann J. Development of a WHO growth reference for school-aged children and adolescents. Bull World Health Organ. 2007;85(9):660-7.

17. Wamba PC, Enyong Oben J, Cianflone K. Prevalence of overweight, obesity, and thinness in Cameroon urban children and adolescents. J Obes. 2013; 2013:737592.

18. Armstrong ME, Lambert MI, Sharwood KA, Lambert EV. Obesity and overweight in South African primary school children - the health of the nation study. S Afr Med J. 2006;96(5):439-44.

19. Ogden CL, Carroll MD, Kit BK, Flegal KM. Prevalence of obesity and trends in body mass index among US children and adolescents, 1999-2010. JAMA. 2012;307(5):483-90.

20. Gewa CA. Childhood overweight and obesity among Kenyan pre-school children: association with maternal and early child nutritional factors. Public Health Nutr. 2010;13(4):496-503.

21. Monteiro CA, Moura EC, Conde WL, Popkin BM. Socioeconomic status and obesity in adult populations of developing countries: a review. Bull World Health Organ. 2004;82(12):940-6.

22. Malik VS, Schulze MB, Hu FB. Intake of sugar-sweetened beverages and weight gain: a systematic review. Am J Clin Nutr. 2006;84(2):274-88.

23. Tudor-Locke C, Ainsworth BE, Popkin BM. Active commuting to school: an overlooked source of childrens' physical activity? Sports Med. 2001; 31(5):309-13.

\section{Submit your next manuscript to BioMed Central and we will help you at every step:}

- We accept pre-submission inquiries

- Our selector tool helps you to find the most relevant journal

- We provide round the clock customer support

- Convenient online submission

- Thorough peer review

- Inclusion in PubMed and all major indexing services

- Maximum visibility for your research

Submit your manuscript at www.biomedcentral.com/submit 